\title{
Simulasi Implementasi Load Balancing PCC Menggunakan Simulator Gns3
}

\author{
*Andi Marwan Elhanafi ${ }^{1}$, Imran Lubis ${ }^{2}$, Dedy Irwan $^{3}$, Abdullah Muhazir ${ }^{4}$ \\ Address: $\quad$ Universitas Harapan Medan, Fakultas Teknologi Dan Komputer, Program Studi Teknik Informatika, \\ Indonesia ${ }^{1,2,3}$ Institut Teknologi Medan, Fakultas Teknik, Program Studi Teknik Informatika, Indonesia 4 \\ Email: andimarwanelhanafi@gmail.com ${ }^{1}$,imran.loebis.medan@gmail.com², dedy_irwan.unhar@harapan.ac.id ${ }^{3}$, \\ muhazir@itm.ac.id ${ }^{4}$ \\ * Corresponding Author
}

\begin{abstract}
Abstrak
Kebutuhan komunikasi saat ini sangat penting seiring dengan kemajuan dan perkembangan teknologi komunikasi data yang semakin canggih. Teknologi komunikasi data yang berkembang dari waktu ke waktu sangat pesat. Oleh sebab itu, diperlukan perancangan yang tepat dan handal dalam membangun kualitas jaringan yang baik supaya dapat meningkatkan kinerja dari jaringan tersebut.Dalam hal ini menyebabkan semakin meningkatnya permintaan akan kebutuhan informasi dalam internet, sehingga trafik dalam internet semakin padat oleh permintaan-permintaan akan informasi. Salah satu cara yang dapat digunakan untuk tetap menjaga kualitas koneksi internet adalah dengan menjaga trafik agar tetap berjalan seimbang dan menghemat bandwidth dengan membagi beban ke beberapa jalur atau link dengan menggunakan teknik load balancing dengan menggunakan metode Pcc (Per Connection Classifier). Berdasarkan penelitian yang telah dilakukan maka beban trafick yang diperoleh jadi lebih lancer tanpa ada penumpukan data.
\end{abstract}

Keywords - Load Balancing, Metode Pcc, Bandtwidth

\section{Latar Belakang}

Kebutuhan komunikasi saat ini sangat penting seiring dengan kemajuan dan perkembangan teknologi komunikasi data yang semakin canggih. Teknologi komunikasi data yang berkembang dari waktu ke waktu sangat pesat. Oleh sebab itu, diperlukan perancangan yang tepat dan handal dalam membangun kualitas jaringan yang baik. Dalam lalu lintas suatu jaringan, server mempunyai peran yang sangat penting [1].

Perkembangan pemakaian internet yang meningkat pesat saat ini menyebabkan permintaan akan mutu layanan (Quality of services / QoS) yang harus ditingkatkan. Maka diperlukan pengaturan beban trafik jaringan agar beban menjadi rata dan seimbang. Salah satu solusi yang dapat digunakan untuk tetap menjaga kualitas koneksi internet dengan menjaga trafik tetap berjalan seimbang dan menghemat bandwidth adalah dengan membagi beban ke beberapa jalur atau link dengan menggunakan teknik load balancing. Load balancing merupakan suatu teknik yang digunakan untuk memisahkan antara dua atau banyak network link, dengan mendistribusikan beban trafik pada dua atau lebih jalur koneksi secara seimbang sehingga trafik dapat berjalan optimal [2].

Selama ini masih banyak orang yang beranggapan salah tentang load balancing, bahwa dengan menggunakan load balance dua jalur koneksi, maka besar bandwidth yang akan didapatkan menjadi dua kali lipat dari bandwidth sebelum menggunakan load balance atau dalam kata lain akumulasi dari kedua bandwidth tersebut.

Load Balancing adalah sebuah konsep yang gunanya untuk menyeimbangkan beban atau muatan pada infrastruktur Teknologi Informasi sebuah perusahaan / instansi. Agar seluruh departemen / bagian dapat memanfaatkan secara maksimal dan optimal yang

Program Studi Teknik Informatika 
berfungsi menggabungkan beberapa line Internet Service Provider [3].

PCC (Per Connection Classifier) merupakan salah satu metode yang dapat digunakan pada load balancing, dengan PCC dapat digunakan untuk mengelompokan trafik koneksi yang melalui atau keluar masuk router menjadi beberapa kelompok. Pengelompokan ini bisa dibedakan berdasarkan src-address, ds address, src-port dandst-port [1].

Kelebihan metode PCC adalah mampu men spesifikasikan gateway untuk tiap paket data yang masih berhubungan dengan data yang sebelumnya sudah dilewatkan pada salah satu gateway. Dengan munculnya berbagai metode yang digunakan pada load balancing yang salah satunya adalah metode PCC. Oleh karena itu, dalam penelitian ini akan menjelaskan tentang implementasi Load Balancing metode PCC (Peer Connection Classifier) dengan menggunakan Simulator Gns3. Diharapkan metode PCC ini dapat dijadikan solusi lain dalam penerapan penggunaan metode load balancing pada kantor tersebut. Penelitian ini akan diimplemetasikan menggunakan software network simulator GNS3.

\section{Metode}

\subsection{Load Balancing}

Load Balancing adalah sebuah konsep yang gunanya untuk menyeimbangkan beban atau muatan pada infrastruktur Teknologi Informasi sebuah perusahaan/instansi.Agar seluruh departemen/bagian dapat memanfaatkan secara maksimal dan optimal yang berfungsi menggabungkan beberapa line Internet Service Provider. Jaringan sangat penting bila skala dalam jaringan komputer makin besar demikian juga traffic data yang ada dalam jaringan komputer makin lama makin tinggi. Load balancing atau penyeimbangan beban dalam jaringan sangat penting bila skala dalam jaringan komputer makin besar demikian juga traffic data yang ada dalam jaringan komputer makin lama makin tinggi.

Layanan Load Balancing memungkinkan pengaksesan sumber daya dalam jaringan didistribusikan ke beberapa host lainnya agar tidak terpusat sehingga unjuk kerja jaringan komputer secara keseluruhan bisa stabil. Ketika sebuah sebuah server sedang diakses oleh para pengguna, maka sebenarnya server tersebut sebenarnya sedang terbebani karena harus melakukan proses permintaan kepada para penggunanya. Jika penggunanya banyak maka prosesnyapun banyak.Session-session komunikasi dibuka oleh server tersebut untuk memungkinkan para pengguna menerima servis dari server tersebut.Jika satu server saja terbebani, tentu server tersebut tidak bisa banyak melayani para penggunanya karena kemampuan melakukan processing ada batasnya. Solusi yang paling ideal adalah dengan membagi-bagi beban yang datang ke beberapa server. Jadi yang melayani pengguna tidak hanya terpusat pada satu perangkat saja.Teknik ini disebut Teknik Load Balancing [3].

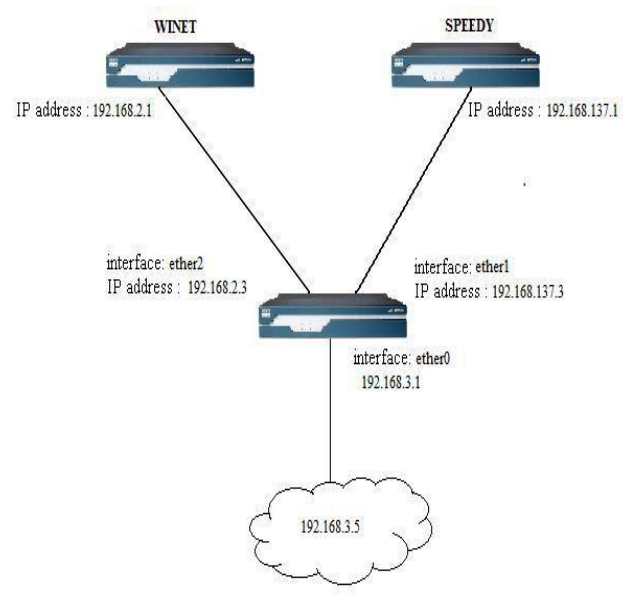

Gambar 1. Topologi load balancing [4]

Adapun manfaat dari Load Balancing :

a. Menjamin Reliabilitias layanan berarti kepercayaan terhadap sebuah sistem untuk dapat terus melayani pengguna dengan sebaikbaiknya. Jaminan realibilitas memungkinkan pengguna dapat melakukan pekerjaan sebaikbaiknya dengan lancar melalui layanan tersebut.

b. Skalabilitas dan ketersediaan Jika dalam sebuah jaringan komputer jika hanya terdapat satu buah server mempunyai pengertian terdapat satu titik masalah. Seandainya tiba-tiba server itu mati maka layanan terhadap pengguna akan terganggu. Dengan melakukan penambahan server dan membentuk serverfarm maka skalabilitasakan meningkat dan selain itu faktor ketersediaan juga akan meningkat.

\subsection{PCC (Per Connection Clasifier)}

Metode PCC (Per Connection Clasifier) merupakan salah satu metode yangdapat digunakan pada load balancing, dengan PCC dapat digunakan untukmengelompokan trafik koneksi yang melalui router menjadi beberapakelompok, sehingga router akan mengetahui jalur gateway yang dilewatidiawal trafik koneksi dan pada paket-paket selanjutnya yang masih

Program Studi Teknik Informatika 
berkaitandengan koneksi awalnya akan dilewatkan pada jalur gateway yang sama juga [5].

Load Balancing dengan metode PCC dilakukan dengan mengambil sejumlah field tertentu dari header IP dan membaginya menjadi nilai 32 bit menggunakan algoritma hashing. Algoritma hashing adalah algoritma untuk mengubah sebuah nilai string atau karakter menjadi sebuah nilai 32 bit yang sudah pasti, sehingga paket dengan header IP yang sama akan menghasilkan nilai hashing yang sama. Parameter yang dapat dijadikan feeder dalam algoritma hashing adalah source-address, destination-address, source-port dan destination-port [6].

PCC bekerja dengan mengelompokkan koneksi yang keluar dan memasuki router menjadi beberapa kelompok yang ditentukan dari hasil algoritmahashing dan dibagi sesuai dengan jumlah yang sudah ditentukan oleh user. Sebagai contoh input fungsi hash adalah IP 1.1.1.1 sebagai alamat IP sumber, 10000 sebagai port TCP sumber, 2.2.2.2 sebagai alamat IP tujuan dan 80 sebagai port tujuan TCP. Output yang dihasilkan adalah $1+1+1$

$+1+10000+2+2+2+2+80=10092$, angka terakhir adalah 2, sehingga output hash adalah 2 . Hal ini akan tetap menghasilkan 2 setiap kali diberi input kombinasi alamat IP dan port yang sama. Fungsi hash akan selalu menghasilkan input yang sama ketika diberi output yang sama.

Berikut ini adalah pilihan bidang yang dapat digunakan dengan tujuan untuk mencocokkan paket yang akan dimasukkan ke dalam algoritma hashing untuk tujuan menyebarkan beban di link dan memutuskan dimana paket akan ditempatkan :
1. src-address
2. dst-address
3. both-address
4. src-port
5. dst-port
6. both-port
7. src-address-and-port
8. dst-address-dan-port
9. both-address-and-port

Router akan melakukan pencatatan terhadap jalur gateway yang dilewati di awal koneksi, sehingga pada paket-paket selanjutnya yang masih berkaitan dengan koneksi awalnya akan dilewatkan melalui jalur gateway yang sama. Hal ini membuat PCC memiliki kelebihan dibandingkan metode load balancing yang lain, dimana sering terjadi kegagalan yang disebabkan oleh perpindahan gateway.
Metode PCC ini tidak melakukan pemecahan paket, melainkan hanya melakukan penandaan pada koneksi sesuai dengan parameter yang diberikan. Routing yang dilakukan adalah membagi beban pada jalur dengan melihat source-address, destination-address, sourceport, dan destination-port yang disesuaikan dengan hashing table dan pengaturan mangle.

\subsection{GNS (Graphical Network Simulator 3)}

GNS3 adalah sebuah program graphical network simulator yang dapat mensimulasikan topologi jaringan yang lebih kompleks dibandingkan dengan simulator lainnya. Program ini dapat dijalankan di berbagai sistem operasi, seperti Windows, Linux, atau MacOS X. Untuk memungkinkan simulasi lengkap, GNS3 memiliki beberapa komponen yaitu:

1. Dynamips merupakan software yang dibuat oleh Christophe Fillot. Software ini untuk mensimulaikan IOS router Cisco seri 1700, 2600, 3600, 3700, dan 7200. Dynamips dikembangkan untuk keperluan training, testing, eksperimen, dan menguji kualitas konfigurasi IOS pada router secara real.Software ini berbasis CLI dan tidak memiliki mode GUI sehingga harus memahami perintah-perintahnya. Dynamips mampu berjalan dibeberapa sistem operasi seperti linux dan windows.

2. Dynagen dibuat oleh Greg Anuzelli merupakan program front-end untuk dynamips yang berfungsi untuk menyederhanakan konfigurasi dynamips.

3. Untuk membuat suatu simulasi jaringan di GNS3 terkadang kita memerlukan keberadaan end user device untuk keperluan testkoneksi end to end sehingga simulasi routing menjadi terasa lebih realistis. Qemu merupakan aplikasi emulator yang mengandalkan translasi binary untuk mencapai kecepatan yang layak saat berjalan di arsitektur komputer host. Dalam hubungannya dengan komputer host, Qemu menyediakan satu perangkat model yang memungkinkan untuk menjalankan berbagai sistem operasi yang belum dimodifikasi sehingga dapat ditampilkan dalam hosted virtual machine monitor. Qemu juga dapatmemberikan dukungan percepatan modus campuran binary translation (untuk kernel code) dan native execution (untuk user code).

4. WinPcap adalah tool standar yang digunakan pada industri untuk mengakses link-layer 
network pada lingkungan kerja Windows. WinPCap mengizinkan aplikasi untuk mengambil dan mentransmisikan paket-paketjaringan, serta mendukung kernel-level packet filtering, network statistics engine, dan remote packet capture.

5. Merupakan emulator $P C /$ node. Prinsip kerja dari GNS3 adalah mengemulasi Cisco IOS pada komputer, sehingga $P C$ dapat berfungsi layaknya sebuah atau beberapa router bahkan switch, dengan cara mengaktifkan fungsi dari EthernetSwitch Card.

Fitur-fitur yang didukung GNS3 antara lain:

1. Desain jaringan kualitas tinggi dan topologi jaringan yang kompleks.

2. Mengemulasikan berbagai platform Cisco IOS router, IPS, PIX dan ASA firewall, JUNOS.

3. Simulasi Ethernet sederhana, ATM dan Frame Relay switch.

4. Koneksi antara jaringan simulasi dengan jaringan yang sesungguhnya di dunia nyata.

5. Dapat dihubungkan ke jaringan fisik.

6. Dapat diintegrasikan dengan Wireshark (tools packet capture/analyzer) untuk analisa traffic jaringan.

Kelebihan Menggunakan GNS3 :

1. IOS yang digunakan real, maka seakan-akan melakukan konfigurasi pada router sungguhan.

2. GNS3 memungkinkan untuk menjalankan routerhigh end (seri 3600, maupun 7200 ) yang tidak bisa dijalankan pada Packet Tracer. Pada GNS3 kita juga dapat menjalankan router Firewall(PIX)[7].

\section{Hasil}

Dalam penelitian ini, penulis mencoba untuk merancang jaringan load balancing dengan menggunakan Gns3 (graphical network simulator 3). Gns3 adalah aplikasi yang digunakan khusus untuk merancang suatu simulasi jaringan komputer baik berbentuk lan ataupun berbasis wan dan man. aplikasi ini bisa mensimulasikan jaringan yang luas hingga bisa mencangkup suatu negara atau benua.aplikasi ini hampir mirip dengan aplikasi simulasi jaringan tentapi aplikasi gns3 ini memiliki banyak kelebihan diantaranya adalah sebagai berikut:

1. IOS yang digunakan real, maka seakan-akan melakukan konfigurasi pada router sungguhan.
2. Gns3 memungkinkan untuk menjalankan router high end (seri 3600, maupun 7200) yang tidak bisa dijalankan pada packet tracer. Pada gns3 kita juga dapat menjalankan router firewall (pix).

Perancangan load balancingdan pembagian bandwidth pada jaringan LAN menggunakan mikrotik routeryang akan dilakukan dengan menggunakan topologi berikut.pada gambar dibawah ini adalah skema dari rancangan 2 ISP (internet service propider).

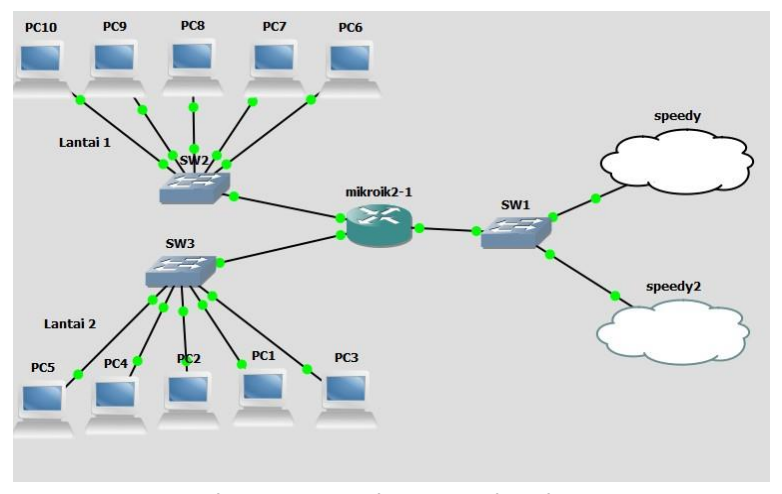

Gambar 2. Topologi Load Balancing

Konfigurasi komputer client yang akan dilakukan adalah dengan memberikan nama pada setiap komputer client, kemudian pemberian IP address, Adapun IP yang akan digunakan pada Komputer client sebagai berikut.

\section{KOMPUTER PC 1:}

IP Address

: 172.168.1.2

Subnet Mask

Default Gateway

: 172.168.1.1

KOMPUTER PC 2:

IP Address

: 172.168 .1 .3

Subnet Mask

Default Gateway

: 172.168.1.1

KOMPUTER PC 3:

IP Address

: 172.168.1.4

Subnet Mask

: 255.255.255.0

Default Gateway

: 172.168.1.1

KOMPUTER PC 4:

IP Address

: 172.168.1.5

Subnet Mask

: 255.255.255.0

Default Gateway

: 172.168.1.1

KOMPUTER PC 5:

Program Studi Teknik Informatika 


$\begin{array}{ll}\text { IP Address } & : 172.168 .20 .2 \\ \text { Subnet Mask } & : 255.255 .255 .0 \\ \text { Default Gateway } & : 172.168 .20 .1 \\ \text { KOMPUTER PC 6: } & \\ \text { IP Address } & : 172.168 .20 .3 \\ \text { Subnet Mask } & : 255.255 .255 .0 \\ \text { Default Gateway } & : 172.168 .20 .1 \\ & \\ \text { KOMPUTER PC 7: } & : 172.168 .20 .4 \\ \text { IP Address } & : 255.255 .255 .0 \\ \text { Subnet Mask } & : 172.168 .20 .1 \\ \text { Default Gateway } & \\ \text { KOMPUTER PC 8: } & : 172.168 .20 .5 \\ \text { IP Address } & : 255.255 .255 .0 \\ \text { Subnet Mask } & : 172.168 .20 .1 \\ \text { Default Gateway } & \end{array}$

Setting interface mikrotik router dilakukan untuk memudahkan dalam membedakan antara port ether link dengan port ether jaringan LAN. Adapun alokasi namaport ether pada mikrotik yang akan digunakan. Untuk menjalankan mikrotik, klik kanan mikrotik yang terdapat pada gns3 kemudian klik start, lalu mikrotik akan secara otomatis terhubung pada virtualbox.

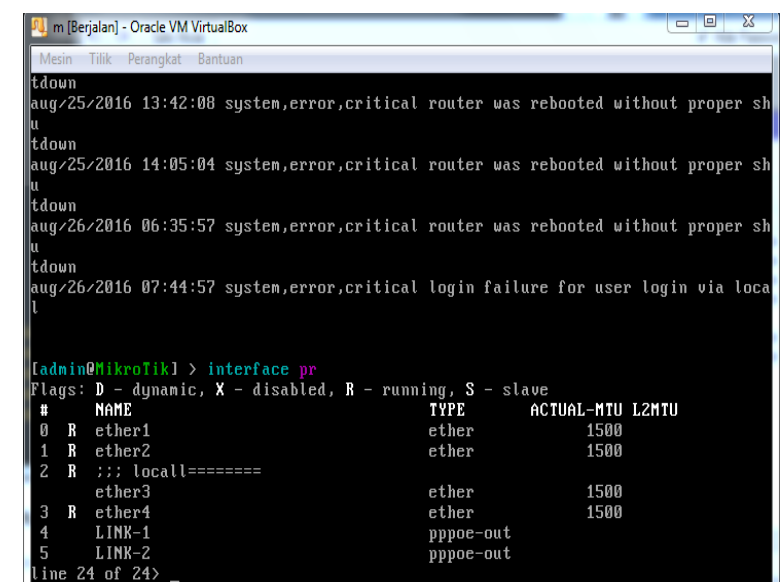

Gambar 3. Interface VirtualBox.

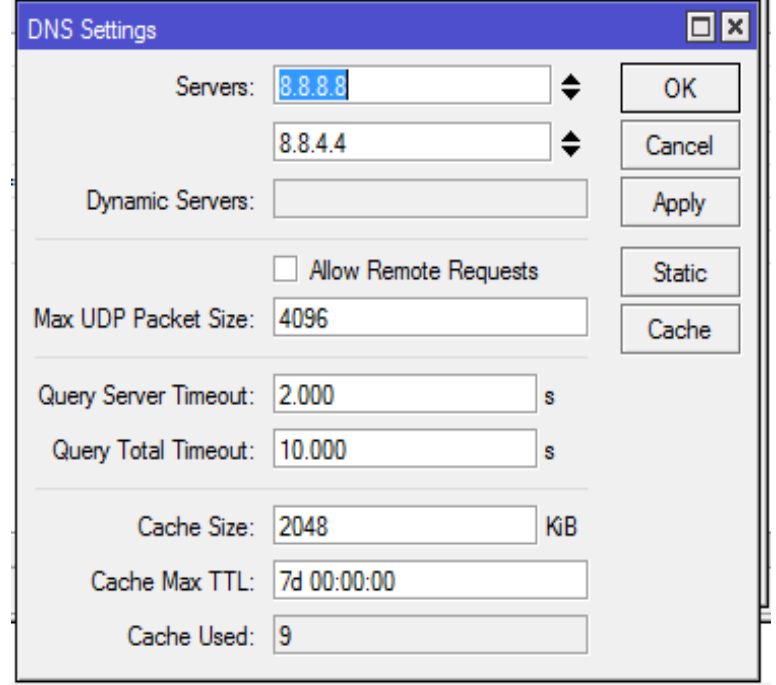

Gambar 4. Tampilan Setting DNS

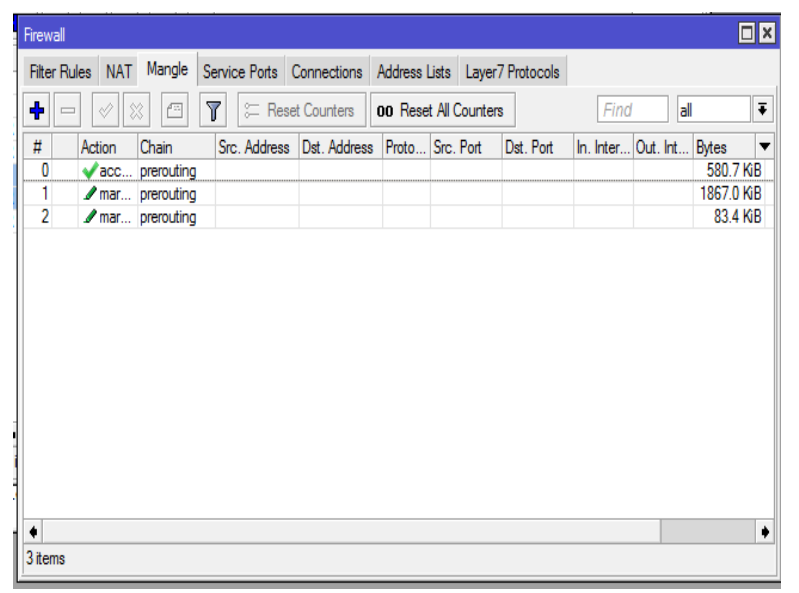

Gambar 5. firewall magle rule

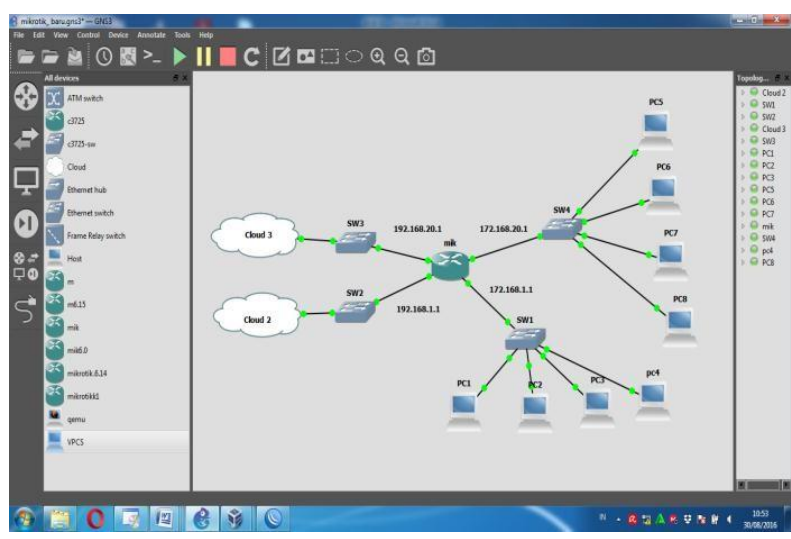

Gambar 6. Perancangan di Aplikasi GNS3

Program Studi Teknik Informatika 


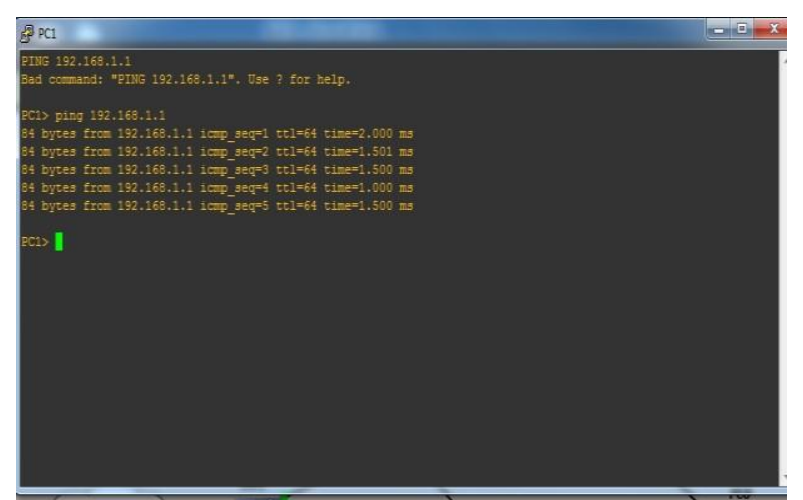

Gambar 7. Pengujian Ping PCL

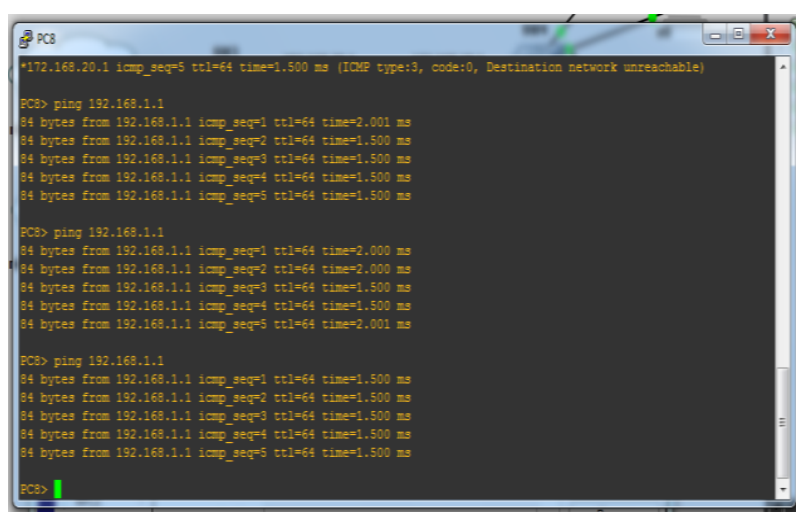

Gambar 8. Pengujain Ping PC8

\section{Kesimpulan}

Penggunaan load balancing yang dilakukan dengan menggabungkan dua gateway ISP menjadi satu jaringan, Loadbalancing dan pembagian akses jaringan dilakukan dengan menggunakan mikrotik. pada penelitian ini dilakukan hanya pada jaringan Lan, dan tidak terhubung pada internet jadi jaringan yang dihasilkan hanya terlihat dari hasil uji coba pengepingan yang dilakukan melalui $p c$ ke router. Dengan menggunakan load balancing metode pcc, beban trafick yang diperoleh jadi lebih lancar tanpa ada penumpukan data. Jika salah satu dari jaringan tersebut mati maka akses internet akan tetap berjalan karena masih ada jaringan yang satunya lagi sebagai penyedia internet (isp). Jika tiap-tiap komputer akan mengakses jaringan makan akan secara otomatis komputer tersebut memilih jaringan yang telah ditentukan.

\section{Acknowledgement}

Penulis mengucapkan Terima kasih kepada Universitas Harapan Harapan Medan dan Institut Teknologi Medan.

\section{References}

[1] Ilza, Rosida. 2012. Implementasi Load Balancing Menggunakan Metode Pcc (Per Connection Classifier) Pada IPv4, Program Studi Teknik Informatika Fakultas Teknologi Industri Universitas Pembangunan Nasional "Veteran", JawaTimur.

[2] Canggih Ajika Pamungkas. 2016. Manajemen bandwith menggunakan mikrotik router board di politeknik indonusa : Surakarta.

[3] Esti, Yuliana. 2012. Mengimplementasikan Load Balancing Untuk jaringan, Sekolah Tinggi Manajemen Informatika Dan Komputer (STMIK) Widya Utama :Purwokerto.

[4] Nurul Fadilah, Zamzami. 2012. Implementasi load balancing dan failover menggunakan mikrotik router os berdasarkan multi home gatewaye pada warung internet "diga". Politeknik Telkom : Bandung.

[5] Fiki Justisia, Bhayangkara, Imam Riadi. 2014. Implementasi Proxy Server Dan Load Balancing Menggunakan Metode Per Connection Classifier (Pcc) Berbasis Mikrotik. Program Studi Teknik Informatika Universitas Ahmad Dahlan : Yogyakarta.

[6] Fata, Nidaul Khasanah, Muhammad Kusban, S.T., M.T. 2014. Perancangan dan Simulasi Jaringan Komputer Menggunakan graphical network simulator 3 (GNS3). Program Studi Teknik Informatika Fakultas Komunikasi Dan Informatika Universitas Muhammadiyah: Surakarta.

[7] Recky, Setia Herdiansyah. 2015. Analisis Perbandingan Quality Of Service Load Balancing Menggunakan Metode Nth Dan Pcc (Per Connection Classifier), Program Studi Teknik Informatika Fakultas Teknik Universitas Widyatama, Bandung

\section{Biografi Penulis}

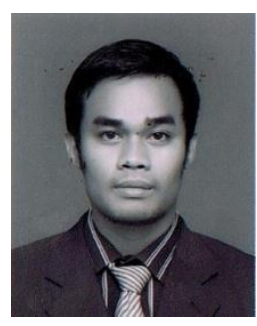

Andi Marwan Elhanafi, Lahir di Medan, 15 Oktober 1986. Pendidikan Strata 1 (S1) Program Studi Teknik Informatika di Sekolah Tinggi Teknik HarapanMedan yang sekarang telah menjadi Universitas Harapan Medan dan Strata 2 (S2) Magister IImu Komputer Program Studi IImu Komputer di Pascasarjana Universitas Sumatera Utara (USU). Merupakan pengajar di Universitas Harapan Medan, Fakultas Teknologi Dan Komputer, Program Studi

Program Studi Teknik Informatika 
Teknik Informatika, Sumatera Utara. Minat penelitian saat ini meliputi bidang Kriptografi.

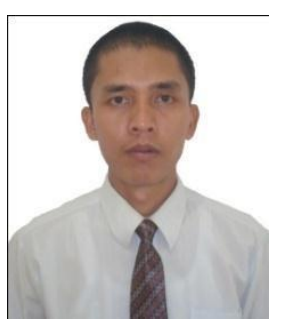

Imran Lubis, Lahir di Medan, 3 November 1978. Pendidikan Strata 1 (S1) Program Studi Tek nik Informatika di Sekolah Tinggi Teknik HarapanMedan yang sekarang telah menjadi Universitas Harapan Medan dan Strata 2 (S2) Magister Teknik Informatika Sekolah Tinggi Manajemen Informatika Komputer ERESHA. Merupakan pengajar di Universitas Harapan Medan, Fakultas Teknologi Dan Komputer, Program Studi Teknik Informatika, Sumatera Utara. Minat penelitian saat ini meliputi bidang artificial intelligence, microcontroller dan decission support system.

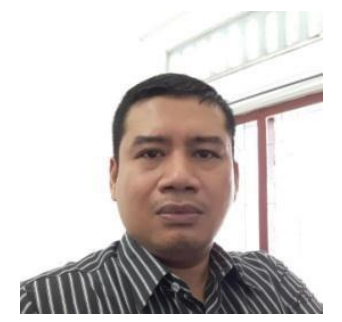

Dedy Irwan, Lahir di Balige, 25 September 1977. Pendidikan Strata 1 (S1) Program Studi Teknik Informatika di Sekolah Tinggi Teknik Harapan Medan yang saat ini telah menjadi Universitas Harapan Medan dan Strata 2 (S2) Magister Teknik

Informatika Program Studi Teknik Informatika di Fakultas Ilmu Komputer dan Teknologi İnformasi Universitas Sumatera Utara. Merupakan pengajar di Universitas Harapan Medan, Fakultas Teknik dan Komputer, Program Studi Sistem Informasi, Sumatera Utara. Minat penelitian saat ini meliputi bidang Artificial Intelligence dan Information Technology.

Program Studi Teknik Informatika 